\title{
Article
}

\section{Quality in Tourism Literature: A Bibliometric Review}

\author{
Fernando J. Garrigos-Simon ${ }^{1}$, Yeamduan Narangajavana-Kaosiri ${ }^{2}$ and \\ Yeamdao Narangajavana ${ }^{3, *}$ \\ 1 Department of Business Organization, Universitat Politècnica de València, 46022 Valencia, Spain \\ 2 Department of Business Administration and Marketing, Universitat Jaume I, 12071 Castellón, Spain \\ 3 School of Management, Walailak University, 222 Thaiburi, Thasala, Nakhon Si Thammarat 80160, Thailand \\ * Correspondence: nyeamdao@wu.ac.th; Tel.: +66-7567-2242
}

Received: 31 May 2019; Accepted: 8 July 2019; Published: 16 July 2019

check for updates

\begin{abstract}
The literature about quality has experienced an important expansion in the tourism sector in the last decade. This is a result of the importance of quality issues when attempting to maintain and expand sustainable business models for tourism organizations and destinations, which are critical to strengthen competitiveness in the new framework. This relevance has been reflected in the tourism literature, with numerous papers focusing on the topic of quality. Nevertheless, despite its importance, there is a lack of studies and reviews of this literature. In order to overcome this problem, this paper develops a bibliometric and visualization analysis of the literature that examines the topics of tourism and quality together. Specifically, the article studies the 4625 documents on this issue published until the end of 2018 in the Web of Science Core Collection database, by using the co-occurrence of keywords, co-citation, bibliographic coupling, and co-authorship analyses. In addition, the VOSviewer program was used to map the diverse clusters or relationships among the literature. The results showed the trends and impact of this literature, and also the main papers, authors, journals, institutions, and even countries that focus on tourism and quality aspects together. They are useful for researchers and practitioners when dealing with this topic, in order to better understand the situation of this issue and its development.
\end{abstract}

Keywords: tourism; quality; bibliometric; visualization; competitiveness; sustainability

\section{Introduction}

Quality issues are very important for tourism destinations and organizations to enhance long-term innovation, competitiveness, and sustainability. Hence improving quality in tourism products and services needs the commitment of tourism operators in terms of innovation, continuous improvement, and renewal [1] aimed to enhance tourism industry. However, in the authors' opinion, the search for quality previously requires a deep understanding of what quality is (including the diverse concepts of what it is and its evolution), how it is conceived and perceived by host communities, operators, policymakers, and tourists; and how tourism developments affect opinions, experiences, expectations, and the satisfaction of customers and residents [2]. Moreover, the search for quality issues in the tourism industry, must go further from a simplistic focus on a narrow aspect related to tourism products or services or to the managerial approach. Therefore, a deep review of the literature about quality in tourism literature is needed, in order to understand the complexity of the problem.

The main goal of this paper is to illustrate and carry out a bibliographic and visualization analysis of the literature related to tourism and quality (TQ), when both terms are researched together or simultaneously. The purpose is to observe from this illustration the main factors that authors and practitioners should consider when dealing with quality issues in the tourism sector. In order to attain this goal, this section explains the importance of carrying out bibliometrics to analyze TQ research. 
Then, the paper will analyze some previous similar research, observing the lack of bibliometrics in TQ and the importance and contributions of our paper. Moreover, the following section will analyze the concept and relevance of quality in tourism research, and an investigation, which includes tourism and quality as a managerial approach, but also other factors related to TQ, such as the quality of life, sustainability issues, or diverse topics related to the quality of destinations or the environment among others. Although the relevance of quality issues in tourism has resulted in an exponential growth in research about this topic, very little is known about the extent of quality research related to tourism literature. Bibliometrics is a popular extended method used to analyze this situation. Bibliometrics was conceived as a cross-disciplinary science focused on analyzing bibliographic data quantitatively using statistical and mathematical tools [3]. The method is recognized because of its capability to analyze specific research areas using objective information in an easily handled way [4]. Moreover, the technique is widely used to identify and describe the development of several topics or fields, by also analyzing the main groups of authors, institutions, and areas of research. Hence, bibliometrics is important in tourism as it can analyze and evaluate research quality, interest, and the field of development [5].

The literature offers some research using bibliometric techniques in order to identify pioneering scholars and seminal works in tourism research [6], recent subject areas and citation patterns of tourism research [7], the quality of tourism journals [5], and to analyze special questions in tourism such as psychological research on tourism [8], trends in medical tourism research [9], research on human resources developed in tourism and hospitality management literature [10], and literature about tourism and sustainability [4]. Nevertheless, no bibliometric or visualization analyses about research on quality in tourism were found.

However, despite the lack of bibliometric analyses of TQ, this analysis is useful and important both for authors and for practitioners. For authors it is essential in order to understand the situation of the problem, new trends, and emerging areas, as this study can offer an overview of the research about quality in tourism field and visualize the structure, development, and main trends and impacts of this research. This information is essential as it can offer key points to plan future research. For practitioners and policy makers it is also important, as they need to be more informed in order to lead their actions regarding the kind of tourism developments that are more likely to enhance the competitiveness of firms and destinations, the preservation of the environment and the patrimony for other generations, and also the enhancement of residents' quality of economic and social life. Focusing on this last aspect, the analysis of quality in tourism, together with cooperation among all the actors that participate in the provision of quality products and services, is essential to exceed tourist expectations, which will further ensure sustainability and long term competitiveness of destinations and tourism firms [11].

Due to the lack of bibliometric analysis of the literature about quality issues in tourism, and also due to its importance, this work intends to make an in depth bibliometric analysis of the evolution of TQ literature. The paper considers 4625 works, drawing on data from the Web of Science (WoS). In addition it uses VOSviewer software (version 1.6.9, Leiden University, Leide, The Netherlands) to graphically map the data. Co-occurrence of keywords, co-citation-bibliographic coupling and co-authorship tools were employed.

The study shows a relevant growth in the literature on tourism and quality (TQ) together in the last decade, reaching almost 800 annual papers last years. This literature is led by the journals: Tourism Management, Journal of Travel Research, Journal of Travel Tourism Marketing and Sustainability, and, by institutions from the USA, China, and Spain and by the works of Hoegh et al. [12], Baker and Crompton [13], and Bigne et al. [14] as the most cited papers in TQ. Moreover, the article observes that there are several areas of research. Hence, most of the literature is related to managerial and marketing perspectives, focusing essentially on the relevance of service quality, and its influence on satisfaction and diverse customer behavior. However, other literature also focuses on the quality of life, with environmental and geographical perspectives, centered on destinations and host communities; there also being some relevant research related to rural tourism, medical tourism, economy, and the 
relevance of information technologies and social media in the field. In addition, the literature observes the relevance of some conceptual papers analyzing the term quality $[15,16]$, while methodological research in this field use predominantly structural equation models. The results reveal the complexity of the concept, the main perspectives of $T Q$, and its progression in the literature. Hence, this research provides insights of quality in tourism required for its implications. The insights include the main differences, correlations, and connections of selected parameters. Simply stated, the study can offer an extensive understanding of TQ by clarifying its knowledge, the state of the art, the diverse perspectives, and their connections. Therefore, this paper can help to discover new trends in the tourism and quality field, and their progression, offering an essential understanding for the development of further analyses. These questions are also relevant for policy makers and practitioners, in order to embrace the complexity of the issue.

\section{Literature Review: Tourism and Quality}

The search for a universal definition of quality in the literature can produce inconsistent results, as there is no global definition, but it is diversely appropriate under different circumstances $[13,17]$. In an attempt to embrace quality in all sectors, the definitions of quality are perceived from diverse fields including philosophy, economics, marketing, and operations management, but also environmental and social sciences. For instance, Garvin classifies quality into five perspectives consisting of transcendent perspective, product-based perspective, user-based perspective, manufacturing-based perspective, and value-based perspective [18]. First, transcendent perspective views quality as an innate excellence. Second, product-based perspective views quality as precise and measurable quantities. Third, user-based perspective involves quality in subjective aspect. Fourth, manufacturing-based perspective allows quality to be a conformance of product's specification. Fifth, value-based perspective encompasses an affordable excellence. Actually the business and managerial perspective is the predominant in the literature about quality issues. Hence in terms of the business world, quality was described as the single most important force leading to the economic growth of companies in international markets $[19,20]$. Additionally, it engages profitability and business strategies that drew in customer needs, competitiveness, and continuous quality improvement [18]. Similarly, quality is a strategic issue concerning incorporating customer requirement and experience into company strategic thinking [21].

However the business and managerial perspective is only one of the diverse perspectives analyzing quality issues in tourism. Focusing on tourism industry. UNWTO (World Tourism Organization) defined quality of a tourism destination as:

"the result of a process which implies the satisfaction of all tourism product and service needs, requirements and expectations of the consumer at an acceptable price, in conformity with mutually accepted contractual conditions and the implicit underlying factors such as safety and security, hygiene, accessibility, communication, infrastructure and public amenities and services. It also involves aspects of ethics, transparency and respect towards the human, natural and cultural environment. Quality, as one of the key drivers of tourism competitiveness, is also a professional tool for organizational, operational and perception purposes for tourism suppliers." [22].

Specifically, in tourism and hospitality literature, the top subjects of research related to quality have emphasized, on one hand, the quality of life of tourism destinations and residents (which comprises mainly environmental and social issues related to sustainability), and on the other, essentially the quality of the tourist product and service, as produced or perceived by the customer, and how it affects destination competitiveness and attractiveness.

Concentrating on the first aspect, the literature observes that tourism activities and experiences have an important effect on the quality of life of stakeholders, as they positively affect both tourists' overall life satisfaction and the wellbeing of residents and host communities, in aspects such as cultural life, family life, leisure life, or social life [23]. The main topics of this brand of the literature are related 
to questions related to the quality of life, but also the sustainability and sustainable development of tourism growth. Following this perspective, the literature posits that "the development and growth of tourism depends on its sustainability over time and on its benefits for destinations as a whole" [24] (p. 721). Defined sustainable development as a process that meets the needs of present generations without endangering the ability of future ones to meet their own needs [25] the principles of sustainability and quality combined are extensively applied to tourism research. Specifically these principles try to manage the positive and negative externalities of tourism by making optimal use of resources whilst simultaneously protecting and enhancing them [24], in order to increase the quality of the environment and the quality of life of tourism stakeholders. However such as Garrigos et al., [4] stress, the literature in the tourism field also includes the need to observe quality and sustainability issues to manage and observe not only the environment, but also the ecology, society, landscape, the culture, and the patrimony in the light of the core topics of sustainability. These questions are also reflected in the literature of quality in the tourism field. Hence, diverse geographic, environmental, and even medical and biological perspectives also point to the relevance of quality issues related to the impact of tourism development.

Focusing on the second aspect, quality has been considered an important antecedent of satisfaction and loyalty, and is associated with the performance of the production and service of the product, and as the perception of this process. Specifically, the analysis of quality in the literature is influenced by the development of "Total Quality Management", "Service Quality", and recently "Experiential Quality" concepts. Regarding Total Quality Management, from a managerial approach, it can be conceived of as "a management practice which guarantees an organisation with enhanced performance" [26], and can be associated with innovation and knowledge. Far back in history, quality began as a simple inspection by artisans and was developed to statistical quality control, quality assurance in manufacturing organizations, and to total/strategic quality management. The total/strategic quality management was developed to deal with the needs of a broader quality extent. Considering "Service quality", it is a construct that encompasses quality performance in all activities undertaken by employees and management [27], but with a service focus, and a marketing and consumer perspective. Hence service quality is defined by Parasuraman, Zeithaml, and Berry [15] as "a global judgment, or attitude, related to the superiority of the service", or in the tourism sector as "the total features and characteristics of a product or service that bear on its ability to satisfy stated or implied needs" [28]. The concept emphasizes questions such as satisfaction, as pointed out by Ryan, but also the difference between expectations and perceptions of the product or service received [29,30]. Designing quality in service becomes traditionally commonly accepted methods in service industries [31]. Then, quality of services has been extensively studied by scholars and applied by practitioners in the tourism industry. Considering, experiential quality, with a customer approach, it also includes visitors' cognitive, affective, and attitudinal reflections and responses, and it does not only involve the attributes provided by a supplier, it also involves the attributes brought by the visitor [32]. Hence, while service quality refers to service performance at the attribute level, experiential quality indicates the psychological outcome resulting from visitor participation in tourism activities [33]. This perspective is important, because tourism is a people-based industry, and because the judgments of quality by customers/tourist is inevitable in service encounter, and the quality of all participants in tourism products and services need to be controlled and monitored. Therefore, and to sum up, quality in tourism has been perceived as a critical component for achieving competitiveness, delivering value to tourists and enhancing overall company performance and capabilities [34].

Based on these previous analyses, this paper observes tourism and quality as a multidimensional approach that encompasses the wellbeing (physical, material, ecological, social, and even emotional) of the destinations and the diverse stakeholders involved in the production and consumption of tourism goods and services, and also the features of performance of the tourism product or service as it is expected, perceived, or experienced by the tourist. 
The following section describes the data sources and bibliometric methods used. Section 4 presents the bibliometric results and graphical analysis of the data, and explores the significance of the main findings, and Section 5 provides the discussion and Section 6 the main conclusions.

\section{Materials and Methods}

This research used data from the WoS Core Collection database, which included some sub-databases. The reason for using this database was the fact that it was one of the two most widely recognized international databases, together with Scopus. In addition, this database was chosen as it included the most important journals with the highest standards [35]. Unlike others such as Google, which is criticized for its unreliability [36]. This method followed other previous studies, which opted for this database instead of Scopus $[4,35,37]$.

In order to evaluate only TQ research, were selected all the papers that used the keywords "Quality" and "Tourism" simultaneously for all the knowledge sections or categories of publications in the WoS [38] (led by the area of "hospitality, leisure, sports and tourism", but including the others categories such as "management", "environmental studies", "environmental sciences", and so forth). The population includes all papers since the first article, published in 1990, up to 31 December 2018. Data collection was carried out in February 2019. The total sample was filtered by considering only articles, reviews, letters, and notes [4], using a final sample of 4625 works.

The paper used some of the most popular bibliometric indicators such as: The total number of papers, to measure productivity; and total citations, to assess the relevance of a country, institution, or author [35,39]. In addition, the h-index indicates the quality of a set of papers [38] (the $h$ index for an author, indicates that he/she has at least $\mathrm{H}$ papers cited at least $\mathrm{H}$ times [40]). Other indicators are the number of papers above a number of citations threshold, to analyze the influence of papers [38]; the impact factor provided by the WoS, to observe a journal's dissemination power, [38] and the ratio citations/papers to measure the impact of each document.

In additional to bibliometric measures, the research uses science mapping to map the data, with the VOS viewer software [41]. This tool, broadly used in bibliometric literature [38], draws the structure and networks of authors, journals, universities, and countries. Specifically, the study concentrated on the co-occurrence of author keywords (keywords appearing below the abstract); co-citation [42] (when two papers receive a citation from the same article); bibliographic coupling [43] (when two documents cite the same third paper); and co-authorship (the number of co-authors between the most productive sources) [44]. These analyses are the most widely used in the bibliometric literature [4]. The studies carried out hierarchical cluster analyses.

\section{Results}

The results of this article involved seven analyses. Firstly, the paper concentrated on the situation and progress in research on TQ, also analyzing the citation structure of documents. Secondly, it examined the most cited papers on TQ. The third epigraph analyzed the leading journals. The fourth one focused on the co-occurrence analysis of author keywords in TQ. Fifthly, the article investigated the co-citation of references, journals, and authors regarding TQ. The sixth section explores the bibliographic coupling of authors. Finally, the paper considers the co-authorship networks of countries and institutions.

\subsection{Status and Evolution of Tourism and Quality in the Literature}

The first document related to tourism and quality appeared in the Web of Science (WoS) in 1989, in a conference about water-quality and management of recreation and tourism [45]; however, the first article appeared one year later. Since then, documents have appeared regularly, the growth being substantial in the $90^{\prime} \mathrm{s}$, and especially in the last decades. Hence, from 2008 more than 100 papers were published a year; since 2015 they surpassed 500 a year; and in the last two years they reached almost 800 documents a year. Figure 1 illustrates the annual trends of publications. 


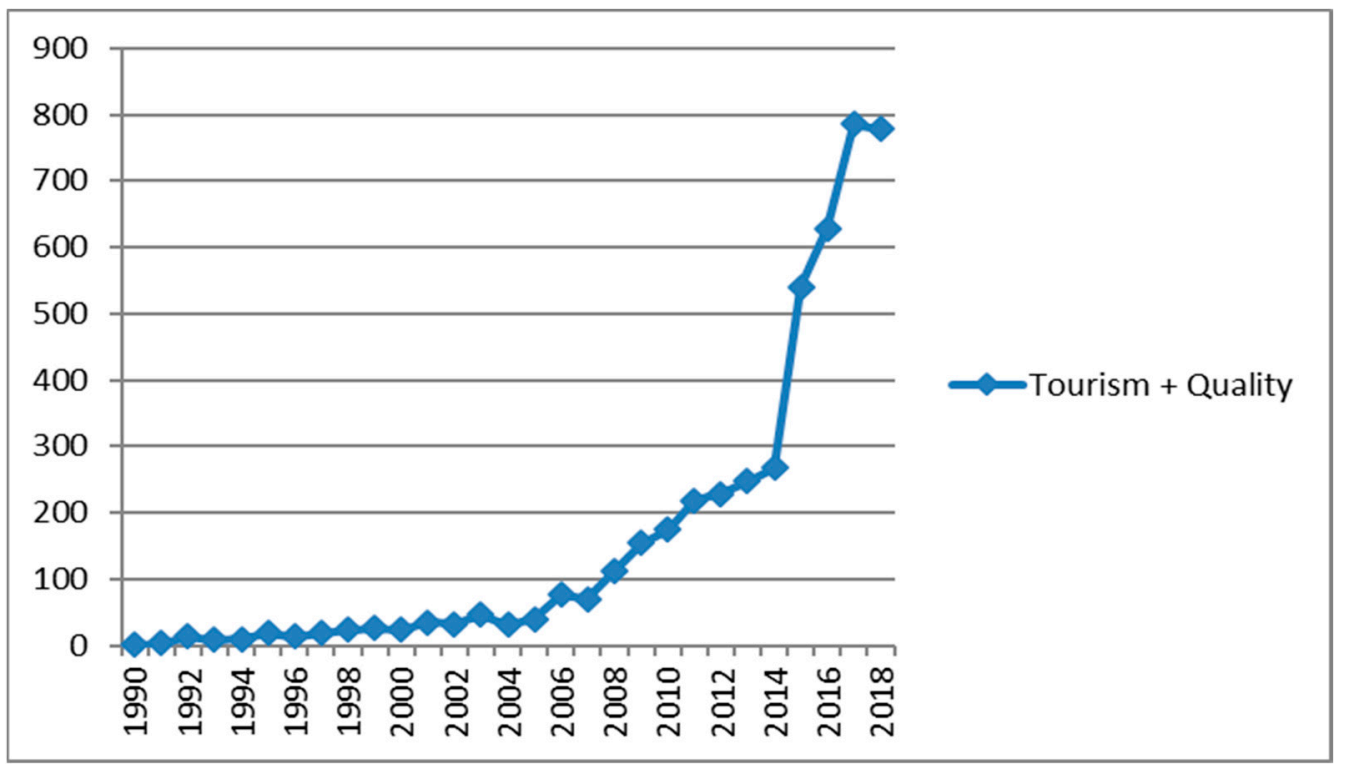

Figure 1. Annual publications in Web of Sciences (WoS) in tourism and quality. Source: Web of Science.

The relevance of the diverse documents could be also shown through an analysis of the citation analysis, or number of citations of the articles published in this field. The most cited paper about tourism and quality was the one by [12], with almost 2500 citations in the WoS, followed by those by Baker and Crompton [13], and Bigne et al. [14], with more than 800 and almost 600 citations respectively in the WoS.

Table 1 illustrates the general citation structure in TQ. Only four papers received more than 500 citations $(0.09 \%)$, and $27.07 \%$ of papers exceeded 10 citations. In addition, and looking at the h-Index [40], which provides a holistic overview of the field [38], the h-index for all the articles related to TQ was 97 (97 papers had 97 or more citations).

Table 1. General citation structure in tourism and quality (TQ) literature.

\begin{tabular}{ccccc}
\hline \multicolumn{5}{c}{ Tourism Quality } \\
\hline $\begin{array}{c}\text { Number of } \\
\text { Citations }\end{array}$ & $\begin{array}{c}\text { Number of } \\
\text { Articles }\end{array}$ & $\begin{array}{c}\text { Accumulated n. of } \\
\text { Articles }\end{array}$ & \% Articles & $\begin{array}{c}\text { \% Accumulated } \\
\text { Articles }\end{array}$ \\
\hline 500 & 4 & 4 & 0.09 & 0.09 \\
$\leq 250$ & 12 & 16 & 0.26 & 0.35 \\
$\leq 100$ & 82 & 98 & 1.77 & 2.12 \\
$\leq 50$ & 167 & 265 & 3.61 & 5.73 \\
$\leq 25$ & 334 & 599 & 7.22 & 12.95 \\
$\leq 10$ & 653 & 1252 & 14.12 & 100.00 \\
$<10$ & 3373 & 4625 & 72.93 & \\
Total & 4625 & Source: The author, based on WoS 2019.
\end{tabular}

\subsection{Top Cited Papers in $T Q$}

Regarding the most influential papers in the field of TQ. Table 2 presents the top 30 papers with the most citations and their characteristics. An examination of the number of citations reveals the quality of a document, and also its popularity and influence within a research field [38].

The article by [12] was ranked in the first position for the number of citations (2472) in the area of TQ, and also for the number of citations per year (224.73). This document analyzed the influence of climate change on coral reefs and water quality, observing their consequences for tourism. The second most cited paper, (820 citations) was a paper by [13], although it was the fourth in number of citations per year (46.06). 
This document analyzed perceived performance quality in tourism, and its effect on satisfaction and the behavioral intentions of tourists. The paper by [14] was ranked third for the number of citations (591), and also for the number of citations per year (53.73), next a paper by Chen and Chen [46] (which, with 60.38 citations a year, analyzed the relationship between experienced quality, perceived value, satisfaction, and behavioral intentions of tourists). The paper by Bigne et al. [14] concentrates on tourism image, positing on its influence on the quality perceived by tourists and examines the relationship between quality and satisfaction and also between these variables and tourist's behavioral variables.

Table 2. Top 30 papers with the highest citations in TQ.

\begin{tabular}{|c|c|c|c|c|c|c|}
\hline \multicolumn{7}{|c|}{ Papers with the Highest Citations in TQ } \\
\hline $\mathbf{R}$ & Journal & Articles & Authors & Year & TC & CY \\
\hline 1 & SC & $\begin{array}{l}\text { Coral reefs under rapid climate change and ocean } \\
\text { acidification }\end{array}$ & $\begin{array}{l}\text { Hoegh-Guldberg, O.; Mumby, P.J.; } \\
\text { Hooten, A.J.; et ál. }\end{array}$ & 2007 & 2472 & 224.73 \\
\hline 2 & ATR & Quality, satisfaction and behavioral intentions & Baker, D.A.; Crompton, J.L. & 2000 & 829 & 46.06 \\
\hline 3 & $\mathrm{TM}$ & $\begin{array}{l}\text { Tourism image, evaluation variables and after } \\
\text { purchase behavior: inter-relationship }\end{array}$ & Bigne, J.E.; Sanchez, M.I.; Sanchez, J. & 2006 & 591 & 53.73 \\
\hline 4 & JBR & Tourism, competitiveness, and societal prosperity & Crouch, G.I.; Ritchie, J.R.B. & 1999 & 532 & 28.00 \\
\hline 5 & $\mathrm{TM}$ & $\begin{array}{l}\text { Experience quality, perceived value, satisfaction and } \\
\text { behavioral intentions for heritage tourists }\end{array}$ & Chen, C.F.; Chen, F.S & 2010 & 483 & 60.38 \\
\hline 6 & $\mathrm{TM}$ & $\begin{array}{c}\text { Examining the structural relationships of destination } \\
\text { image, tourist satisfaction and destination loyalty: An } \\
\text { integrated approach }\end{array}$ & Chi, C.G.Q.; Qu, H. & 2008 & 451 & 45.10 \\
\hline 7 & $\mathrm{TM}$ & $\begin{array}{c}\text { Value dimensions, perceived value, satisfaction and } \\
\text { loyalty: an investigation of university students' } \\
\text { travel behavior }\end{array}$ & Gallarza, M.G.; Saura, I.G. & 2006 & 418 & 34.83 \\
\hline 8 & AJTMH & $\begin{array}{l}\text { Conquering the intolerable burden of malaria: What's } \\
\text { new, what's needed: A summary }\end{array}$ & Breman, J.G.; Alilio, M.S.; Mills, A. & 2004 & 400 & 28.57 \\
\hline 9 & $\mathrm{TM}$ & $\begin{array}{c}\text { The destination product and its impact on } \\
\text { traveller perceptions }\end{array}$ & Murphy, P.; Pritchard, M.P.; Smith, B. & 2000 & 350 & 19.44 \\
\hline 10 & TM & The service experience in tourism & Otto, J.E.; Ritchie, J.R.B. & 1996 & 348 & 15.82 \\
\hline 11 & LO & $\begin{array}{l}\text { Nitrogen and phosphorus inputs control } \\
\text { phytoplankton growth in eutrophic Lake Taihu, China }\end{array}$ & Xu, H.; Paerl, H.W.; Qin, B.; et ál. & 2010 & 345 & 43.13 \\
\hline 12 & ATR & Repeaters' behavior at two distinct destinations & Kozak, M. & 2001 & 320 & 18,82 \\
\hline 13 & $\mathrm{EC}$ & $\begin{array}{l}\text { Development of a multi-dimensional scale for } \\
\text { measuring the perceived value of a service }\end{array}$ & Petrick, J.F. & 2002 & 285 & 17.81 \\
\hline 14 & ATR & Staged authenticity and heritage tourism & Chhabra, D.; Healy, R.; Sills, E. & 2003 & 276 & 18.40 \\
\hline 15 & JST & $\begin{array}{l}\text { Food, place and authenticity: local food and the } \\
\text { sustainable tourism experience }\end{array}$ & Sims, Rebecca & 2009 & 262 & 29.11 \\
\hline 16 & $\mathrm{TM}$ & Revisiting importance-performance analysis & $\mathrm{Oh}, \mathrm{H}$. & 2001 & 252 & 14.82 \\
\hline 17 & ATR & $\begin{array}{l}\text { Value, satisfaction and behavioral intentions in an } \\
\text { adventure tourism context }\end{array}$ & Williams, Paul; Soutar, Geoffrey, N. & 2009 & 243 & 27.00 \\
\hline 18 & ATR & Mindful visitors-Heritage and tourism & Moscardo, G & 1996 & 241 & 10.95 \\
\hline 19 & JTR & $\begin{array}{l}\text { Antecedents of Tourists' Loyalty to Mauritius: The } \\
\text { Role and Influence of Destination Image, Place } \\
\text { Attachment, Personal Involvement, and Satisfaction }\end{array}$ & Prayag, Girish; Ryan, Chris & 2012 & 232 & 38.67 \\
\hline 20 & $\mathrm{TM}$ & $\begin{array}{c}\text { Twenty years on: The state of contemporary } \\
\text { ecotourism research }\end{array}$ & Weaver, David B.; Lawton, Laura J. & 2007 & 228 & 20.73 \\
\hline 21 & $\mathrm{TM}$ & $\begin{array}{l}\text { Environmental management of a tourist } \\
\text { destination-A factor of tourism competitiveness }\end{array}$ & Mihalic, T. & 2000 & 227 & 12.61 \\
\hline 22 & $\mathrm{TM}$ & $\begin{array}{l}\text { Determinants of tourism success for DMOs \& } \\
\text { destinations: An empirical examination of } \\
\text { stakeholders' perspectives }\end{array}$ & $\begin{array}{l}\text { Bornhorst, Tom; Ritchie, J.R. Brent; } \\
\text { Sheehan, Lorn }\end{array}$ & 2010 & 223 & 27.88 \\
\hline 23 & ATR & $\begin{array}{c}\text { Korea's destination image formed by the } 2002 \\
\text { World Cup }\end{array}$ & Lee, C.K.; Lee, Y.K.; Lee, B.K. & 2009 & 221 & 24.56 \\
\hline 24 & $\mathrm{EP}$ & $\begin{array}{l}\text { Using multivariate analyses and GIS to identify } \\
\text { pollutants and their spatial patterns in urban soils in } \\
\text { Galway, Ireland }\end{array}$ & Zhang, C.S. & 2006 & 217 & 18.08 \\
\hline 25 & RSM & $\begin{array}{l}\text { A scoping review of scoping reviews: advancing the } \\
\text { approach and enhancing the consistency }\end{array}$ & $\begin{array}{l}\text { Pham, Mai T.; Rajic, Andrijana; } \\
\text { Greig, Judy D.; et ál. }\end{array}$ & 2014 & 206 & 51.50 \\
\hline 26 & $\mathrm{TM}$ & $\begin{array}{l}\text { Progress in tourism management: A review of } \\
\text { website evaluation in tourism research }\end{array}$ & $\begin{array}{c}\text { Law, Rob; Qi, Shanshan; Buhalis, } \\
\text { Dimitrios }\end{array}$ & 2010 & 201 & 25.13 \\
\hline 27 & $\mathrm{TM}$ & $\begin{array}{l}\text { Investigating the relationships among perceived } \\
\text { value, satisfaction, and recommendations: The case of } \\
\text { the Korean DMZ }\end{array}$ & $\begin{array}{l}\text { Lee, Choong-Ki; Yoon, Yoo-Shik; Lee, } \\
\text { Seung-Kon }\end{array}$ & 2007 & 199 & 18.09 \\
\hline 28 & DSS & $\begin{array}{l}\text { Recommender system application developments: } \\
\text { A survey }\end{array}$ & $\begin{array}{l}\text { Lu, Jie; Wu, Dianshuang; Mao, } \\
\text { Mingsong; et ál. }\end{array}$ & 2015 & 197 & 65.67 \\
\hline 29 & JTR & $\begin{array}{c}\text { Development of a Scale to Measure Memorable } \\
\text { Tourism Experiences }\end{array}$ & $\begin{array}{l}\text { Kim, Jong-Hyeong; Ritchie, J.R. } \\
\text { Brent; McCormick, Bryan }\end{array}$ & 2012 & 189 & 31.50 \\
\hline 30 & TM & Host perceptions of tourism: A review of the research & Sharpley, Richard & 2014 & 184 & 46.00 \\
\hline
\end{tabular}

Source: The author based on WoS 2019. R: Ranking; TC: Total Citations; CY: Citations per year. SC: Science; ATR: Annals of Tourism Research; TM: Tourism Management; AJTMH: American Journal of Tropical Medicine and Hygiene; LO: Limnology and Oceanography; EC: Environmental Conservation; JST: Journal of Sustainable Tourism; JTR: Journal of Travel Research; EP: Environmental Pollution; RSM: Research Synthesis Methods; DSS: Decision Support Systems. 


\subsection{Leading Journals in $T Q$}

The 4625 documents about TQ, were published in 1525 sources. The main categories of publications were Hospitality, Leisure, Sport and Tourism (41.71\%), Management (16.00\%), and Environmental Sciences $(12.97 \%)$. When focusing on the journals related to TQ, $78.7 \%$ of the journals published one or two papers about this topic; 32 published 20 or more; 38 between 10 and 19; 100 between five and nine; and 155 three or four.

1038 publications (22.44\% of the papers) in TQ were published in the top 10 journals (Table 3 ). Specifically, the three top journals by number of publications in TQ were: Tourism Management, with $6.59 \%$ of the total publications, Journal of Travel Research with $2.16 \%$ of the total publications, and Journal of Travel and Tourism Marketing, and Sustainability with 1.90\% of the total papers each. However, the H-index for TQ was led by Tourism Management (68), Annals of Tourism Research (39), and Journal of Travel Research (29).

Table 3. The top 30 journals with TQ publications.

\begin{tabular}{|c|c|c|c|c|c|c|c|c|c|c|c|c|c|}
\hline $\mathbf{R}$ & Journal & APTQ & H-TQ & TAP & TCTQ & ACTQ & PCTQ & \%APTQ & IF & $\leq 200$ & $\leq 100$ & $\leq 50$ & $\leq \mathbf{2 0}$ \\
\hline 1 & TM & 305 & 68 & 2736 & 15174 & 10330 & 49.75 & 11.15 & 5.92 & 7 & 43 & 93 & 167 \\
\hline 2 & JTR & 100 & 29 & 630 & 2942 & 2367 & 29.42 & 15.87 & 5.17 & & 6 & 17 & 48 \\
\hline 3 & JTTM & 88 & 19 & 716 & 1131 & 981 & 12.85 & 12.29 & 1.98 & & & 6 & 18 \\
\hline 4 & S & 88 & 8 & 10395 & 227 & 2115 & 2.58 & 0.85 & 2.08 & & & & 1 \\
\hline 5 & JST & 86 & 22 & 733 & 1760 & 1565 & 20.47 & 11.73 & 3.33 & 1 & 4 & 6 & 25 \\
\hline 6 & IJCHM & 82 & 18 & 884 & 977 & 848 & 11.91 & 9.28 & 2.87 & & & 3 & 17 \\
\hline 7 & APJTR & 80 & 8 & 588 & 304 & 272 & 3.80 & 13.61 & 1.35 & & & & 3 \\
\hline 8 & ATR & 79 & 39 & 1623 & 5197 & 4250 & 65.78 & 4.87 & 5.09 & 3 & 12 & 33 & 55 \\
\hline 9 & $\mathrm{TE}$ & 69 & 11 & 837 & 487 & 443 & 7.06 & 8.24 & 0.94 & & & & 6 \\
\hline 10 & CIT & 61 & 13 & 693 & 663 & 637 & 10.87 & 8.80 & 3.46 & & & 3 & 8 \\
\hline 11 & IJTR & 59 & 21 & 594 & 1053 & 961 & 17.85 & 9.93 & 2.45 & & & 4 & 21 \\
\hline 12 & OCM & 56 & 15 & 2757 & 652 & 572 & 11.64 & 2.03 & 2.28 & & & 1 & 11 \\
\hline 13 & IJHM & 55 & 18 & 1281 & 920 & 858 & 16.73 & 4.29 & 3.45 & & & 2 & 18 \\
\hline 14 & JCR & 52 & 10 & 7004 & 518 & 451 & 9.96 & 0.74 & 0.80 & & & 3 & 7 \\
\hline 15 & JDMM & 48 & 10 & 299 & 355 & 327 & 7.40 & 16.05 & 3.67 & & & 1 & 4 \\
\hline 16 & WHTT & 41 & 4 & 234 & 56 & 50 & 1.37 & 17.52 & - & & & & - \\
\hline 17 & SJHT & 32 & 11 & 313 & 253 & 233 & 7.91 & 10.22 & 1.24 & & & & 2 \\
\hline 18 & JHTR & 29 & 14 & 325 & 536 & 510 & 18.48 & 8.92 & 2.69 & & & 3 & 9 \\
\hline 19 & $\mathrm{AE}$ & 28 & 4 & 741 & 51 & 45 & 1.82 & 3.78 & 0.66 & & & & - \\
\hline 20 & TA & 28 & 4 & 204 & 47 & 44 & 1.68 & 13.73 & - & & & & - \\
\hline 21 & TMP & 26 & 6 & 319 & 105 & 104 & 4.04 & 8.15 & 1.78 & & & & 1 \\
\hline 22 & EM & 23 & 11 & 3972 & 329 & 322 & 14.30 & 0.58 & 2.18 & & & & 5 \\
\hline 23 & JBR & 23 & 13 & 5047 & 1192 & 1117 & 51.83 & 0.46 & 2.51 & 1 & 2 & 5 & 12 \\
\hline 24 & JEPE & 23 & 4 & 2373 & 38 & 37 & 1.65 & 0.97 & 0.68 & & & & - \\
\hline 25 & LUP & 23 & 11 & 3399 & 535 & 517 & 23.26 & 0.68 & 3.19 & & 1 & 4 & 9 \\
\hline 26 & TG & 23 & 7 & 365 & 158 & 157 & 6.87 & 6 & 2.07 & & & & 3 \\
\hline 27 & IJCTHR & 22 & 4 & 128 & 39 & 38 & 1.77 & 17.19 & - & & & & - \\
\hline 28 & SPSMEEARD & 22 & 1 & 974 & 4 & 4 & 0.18 & 2.26 & - & & & & - \\
\hline 29 & EJTR & 21 & 3 & 141 & 21 & 17 & 1.00 & 14.89 & - & & & & - \\
\hline 30 & JQAHT & 21 & 3 & 100 & 50 & 49 & 2.38 & 21.00 & - & & & & - \\
\hline
\end{tabular}

Source: The author, based on WoS 2019. R: Ranking; H-TQ: Indicates the H index in the area of tourism quality; APTQ: Articles published in TQ; TAP: Total articles published; TCTQ: Total citations in TQ: ACTQ Articles in which TQ is cited; PCTQ: Average of cites by articles in TQ\%. APTQ: Percentage of articles published in TQ (TQ/TAP); IF: Impact Factor; $\leq 200, \leq 100, \leq 50$, and $\leq 20$ : Articles with more of 200, 100, 50, and 20 citations. TM: Tourism Management; JTR: Journal of Travel Research; JTTM: Journal of Travel Tourism Marketing; S: Sustainability; JST: Journal of Sustainable Tourism; IJCHM: International Journal of Contemporary Hospitality Management; APJTR: Asia Pacific Journal of Tourism Research; ATR: Annals of Tourism Research; TE: Tourism Economics; CIT: Current Issues in Tourism; IJTR: International Journal of Tourism Research; OCM: Ocean \& Coastal Management; IJHM: International Journal of Hospitality Management; JCR: Journal of Coastal Research; JDMM: Journal of Destination Marketing Management; WHTT: Worldwide Hospitality and Tourism Themes; SJHT Scandinavian Journal of Hospitality and Tourism. JHTR: Journal of Hospitality Tourism Research; AE: Amfiteatru Economic; TA Tourism Analysis; TMP: Tourism Management Perspectives; EM: Environmental Management; JBR: Journal of Business Research; JEPE: Journal of Environmental Protection and Ecology; LUP: Land Use Policy; TG: Tourism Geographies; IJCTHR: International Journal of Culture Tourism and Hospitality Research; SPSMEEARD: Scientific Papers Series Management Economic Engineering in Agriculture and Rural Development; EJTR: European Journal of Tourism Research; JQAHM: Journal of Quality Assurance in Hospitality Tourism; IJTC: International Journal of Tourism Cities. 
Concentrating on the top 10 journals, and observing the journals that dedicate the highest number of their published articles to the topic of TQ, they were Journal of Travel Research with almost $16 \%$ of its documents dedicated to TS, followed by Asia Pacific Journal of Tourism Research $(13.61 \%)$, and Journal of Travel and Tourism Marketing (12.21\%). However, among the top 30 sources, the leader was Journal of Quality Assurance in Hospitality and Tourism.

Considering the journals with the highest number of citations per article published about TQ, and looking again at the top 10 journals in number of publications, the ranking was led by Annals of Tourism Research (65.78 citations on average), Tourism Management (49.75), and Journal of Travel Research (29.42). Nevertheless, when analyzing the 30 top journals, the second position was occupied by Journal of Business Research with 51.83 citations on average.

\subsection{Keywords Analysis}

The keyword study observes the distribution of the most frequent keywords. This analysis was developed through keywords co-occurrence. The aim was to visualize the state of the art and the trends of the main research topics in the area of TQ. Specifically, this study focused on the author keywords appearing below the abstract. This technique counts the number of papers in which two keywords appear together. Taking the $4625 \mathrm{TQ}$ related publications, VOS viewer software found 16,004 keywords. From this data, Figure 2 shows the main keywords and the size of the nodes (the larger the keyword and the node, the more papers the keywords appeared in). The lines show the frequent co-occurrence of keywords together in the diverse papers, while the shorter the distance between the nodes, the stronger the relationship these keywords have relatively, comparing co-occurrence with other keywords. The colors of the nodes indicate the different clusters or groups of keywords. In our case, Figure 2 illustrates the existence of seven clusters, by considering a threshold of twenty occurrences, representing the 70 keywords with most frequent co-occurrences. The most frequent keywords, leading the main clusters were: "tourism" (purple), "satisfaction" (red), "service quality" (green), "medical tourism" (light blue), "quality of life" and "sustainability" (both in the same dark blue cluster), "quality" (together with "service quality" in the green cluster), and "rural tourism" (leading the yellow cluster). Apart from these six clusters, "cultural tourism", outside the 30 main keywords, leads a small cluster in orange. Table 4 shows the top 30 keywords, including frequencies and occurrences and total link strengths or co-occurrences.

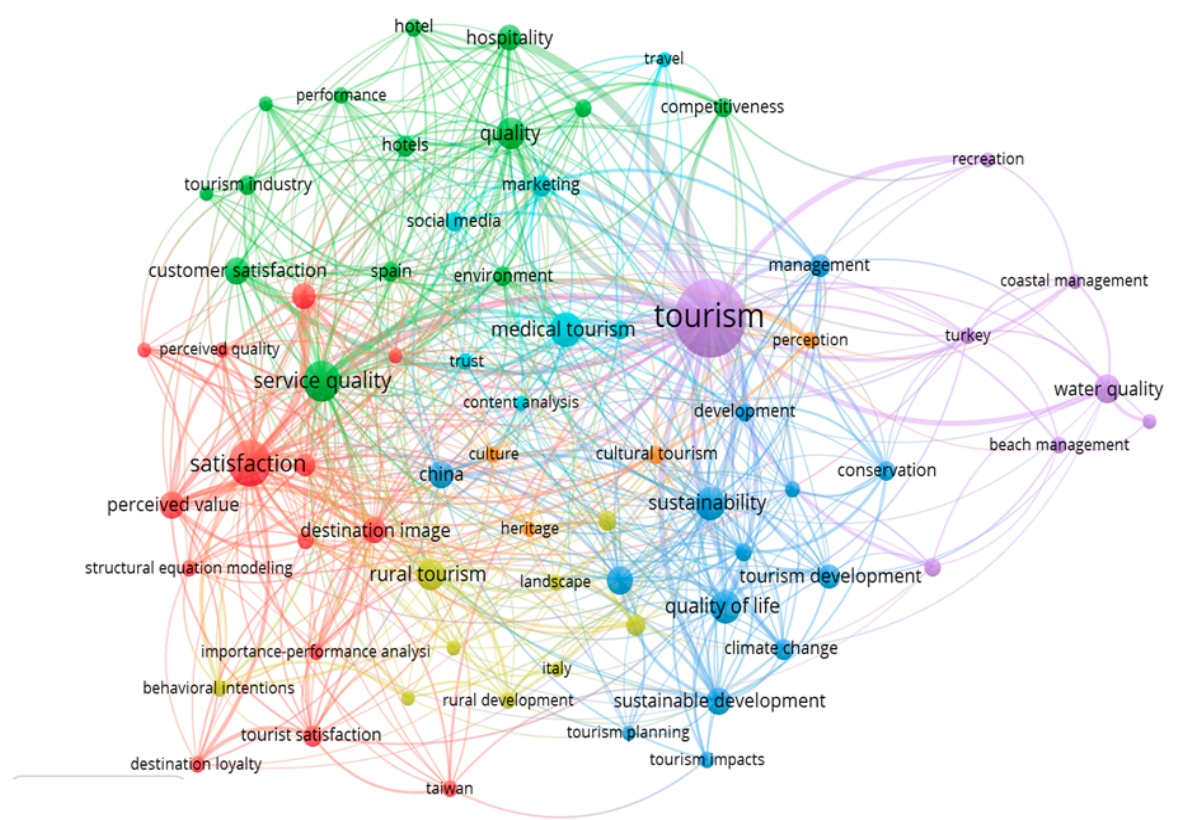

Figure 2. Co-occurrence network of author keywords of TQ-related publications. The figure considers a threshold of twenty occurrences, which shows the 70 keywords with the most frequent co-occurrences, of the 11,596 keywords. 
Table 4. The top author keywords co-occurrence of TQ-related publications.

\begin{tabular}{|c|c|c|c|}
\hline $\mathbf{R}$ & Keyword & Oc & Co \\
\hline 1 & Tourism & 540 & 285.00 \\
\hline 2 & Satisfaction & 194 & 140.00 \\
\hline 2 & Service quality & 151 & 94.00 \\
\hline 3 & Medical tourism & 112 & 37.00 \\
\hline 4 & Quality of life & 99 & 41.00 \\
\hline 5 & Sustainability & 99 & 52.00 \\
\hline 6 & Quality & 88 & 61.00 \\
\hline 7 & Rural tourism & 88 & 48.00 \\
\hline 8 & Sustainable tourism & 76 & 35.00 \\
\hline 9 & Water quality & 74 & 20.00 \\
\hline 10 & Sustainable development & 68 & 39.00 \\
\hline 11 & China & 66 & 34.00 \\
\hline 12 & Customer satisfaction & 65 & 40.00 \\
\hline 13 & Perceived value & 64 & 53.00 \\
\hline 14 & Loyalty & 63 & 60.00 \\
\hline 15 & Hospitality & 62 & 48.00 \\
\hline 16 & Destination image & 60 & 44.00 \\
\hline 17 & Tourism development & 53 & 23.00 \\
\hline 18 & Management & 45 & 29.00 \\
\hline 19 & Motivation & 45 & 25.00 \\
\hline 20 & Hotels & 44 & 20.00 \\
\hline 21 & Marketing & 43 & 35.00 \\
\hline 22 & Tourist satisfaction & 43 & 27.00 \\
\hline 23 & Climate change & 42 & 21.00 \\
\hline 24 & Nature-based tourism & 40 & 18.00 \\
\hline 25 & Competitiveness & 37 & 21.00 \\
\hline 26 & Conservation & 37 & 20.00 \\
\hline 27 & Tourism industry & 37 & 13.00 \\
\hline 28 & Social media & 36 & 18.00 \\
\hline 29 & Spain & 36 & 24.00 \\
\hline 30 & Environment & 34 & 25.00 \\
\hline
\end{tabular}

Source: The author, based on WoS 2019. R: Rank; Oc: Author keyword occurrences; Co: Author keyword co-occurrences link.

\subsection{Reference, Journal, and Author Co-Citation Analysis}

This section looked at the use of the co-citation analysis, focusing on the study of references, journals, and authors. The co-citation study considered when two elements (author, journal, or article) were cited simultaneously by a third paper, as they appeared together in the new reference lists [42]. Moreover, this network analysis permitted study of the characteristics, development, structure, and relationships of TQ, by observing the clusters or relationships within the bibliometric material analyzed.

This study starts by analyzing the network of reference co-citations. The nodes of the study illustrate the relationships between the diverse documents, showing the diverse research themes in TQ. The results, observed in Figure 3, indicate that the ranking was led by one article by Fornell and Larcher [47], followed by two articles by Parasuraman et al. [15,16], which were cited 392, 277, and 242 times in the reference lists of the 4624 documents related to TQ. These documents also led, in the same order, the classification according to the link strength, with values of 389,263, and 229 respectively (one has to point out that the fact of leading this list does not mean that they are included in the list of 4625 documents in the study, but they are co-cited by these documents). The paper by Fornell and Larcher [47] led the cluster in green, the second cluster with 18 items, of the seven clusters shown. The two papers by Parasuraman et al. $[15,16]$ led the third main cluster, with 17 items, in dark blue. However, the cluster with most items was the red one, with 22 items, led by the paper by Baker and Crompton [13], the fourth paper according to the citations (250 citations) and link strength (229), and also the one by Yoon and Uysal [48] (7th in the ranking of citations (185) and link strength (185)). 
The fourth yellow cluster, with 16 items, was led by the papers by Zeithaml [49] and Cronin et al. [50], which were ranked 4th and 6th according to citations (189 and 185 citations) and link strength (189 and 188 also). As for the other clusters, the papers in these other clusters (violet cluster (15 items), light blue (11 items), and orange (four items)) were not ranked among the 30 top documents.

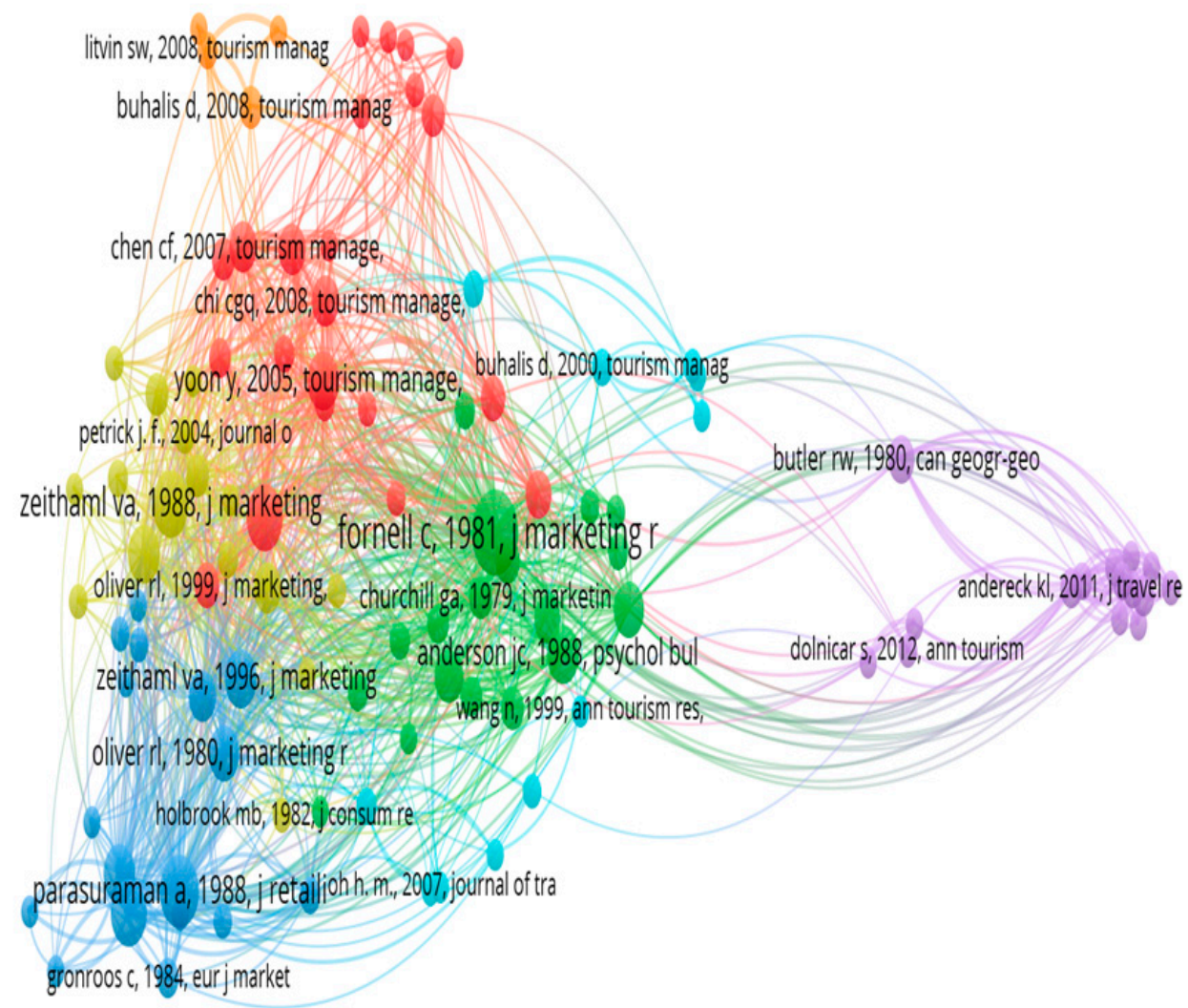

Figure 3. Co-citation of cited references on TQ. One hundred and three references, of the 162968 cited references that met the threshold of a minimum of 50 citations. Source: The author, based on WoS 2019.

The article by Fornell and Larcher [47] is a methodological document about structural equation models. A review of the papers in green reveals that these documents were mainly methodological documents, especially stressing the relevance of structural equation models in these analyses, as for example, the second paper in this cluster, the one by Anderson and Gerbing [51], which ranked eighth in the ranking of cited documents, was also about this tool. The papers by Parasuraman et al. $[15,16]$ are related to service quality in general, and its concept and measurement, specifically in the marketing literature. The cluster that they led was full of papers related to marketing. The main papers in the red cluster were also related to quality, but with more influence in the tourism management literature. For instance, the articles by Baker and Crompton [13] and Yoon and Uysal [48] focus on the relationship between quality, satisfaction, and loyalty and customer behavior in the tourism literature. These same relationships were similar to the ones analyzed in the documents by Zeithaml [49] and Cronin et al. [50], or other papers in this cluster, that emphasized the relevance of the effects of quality on customer intentions in general (and also the relevance of perceptions and value), focusing on industries rather than tourism, but with a marketing or consumer search perspective. The orange cluster included some papers related to information technology, or social media and tourism management. The light blue one had papers related to destination management and the management of experiences. Finally, the papers in the violet cluster, instead of focusing on service quality, emphasized the quality of life, especially among residents, and on the impact of holidays and tourism on the quality of life or on environmental resources, with a variety of managerial, geographical, and environmental perspectives within tourism. 
After studying the network of references, this work focused on the journal co-citation network on TQ (Figure 4). The nodes in this analysis illustrate the activity and number of published documents, while the distance between two papers shows the citation frequency. The results of this study indicate the existence of three main clusters plus a small one. The first red group, with 56 journals, on the left side of the plot, includes journals related to management and marketing, and is led by Journal of Marketing (3325 citations, 2985 link strength), and International Journal of Hospitality Management (3094 citations, 2815 link strength) the fourth and fifth main journals according to the number of citations and link strength. However, it also includes most of the top journals on the study's list, also including Journal of Travel and Tourism Marketing (2050 citations, 1970), Journal of Business Research (1860 citations, 1765), International Journal of Contemporary Hospitality Management (1764 citations, 1646), Journal of Marketing Research (1742 citations, 1662), Journal of Retailing (1506 citations, 1431), and Journal of Consumer Research (1301 citations, 1219), all of them in the 12 top journals. These journals had a mainly managerial or marketing perspective. The second green cluster, with 32 sources, included the three most relevant sources in the figure: Tourism Management, the journal with most citations $(12,910)$ and highest link strength $(10,291)$, Annals of Tourism Research $(8410$ citations, 6739 link strength), and Journal of Travel Research (6979 citations, 6305 link strength). It also included Journal of Sustainable Tourism $(2258,2042)$, the sixth more relevant journal in the study's list. They had a tourism centered perspective. The figure also shows another important cluster, in blue, with 30 items, and with an environmental perspective, which was led by Thesis, outside the main journals but that was cited by 1000 documents. This group also included journals such as Ecological Economics, Landscape and Urban Planning, and Ocean and Coastal Management. Finally, a small yellow cluster only included five items, and it was led by Tourism Economics, as the main source. It had an economic perspective.

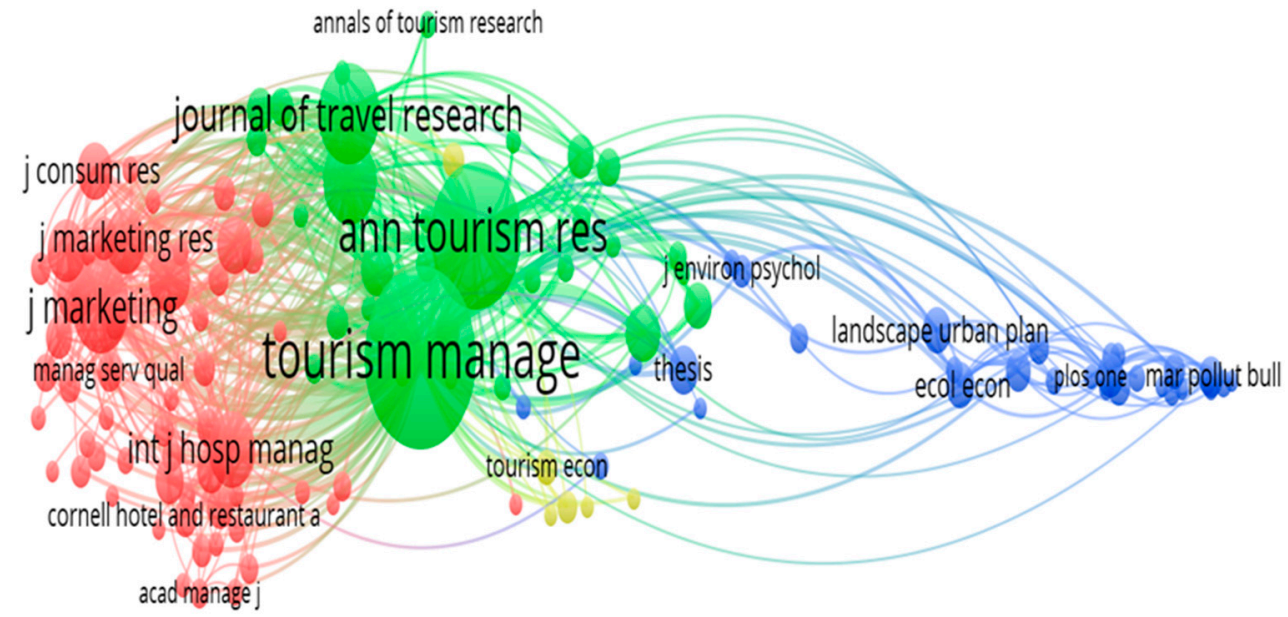

Figure 4. Journal co-citation network on TQ. One hundred and twenty-four main journals, of the 66,125 cited sources by the 4625 documents regarding TQ, which met the threshold of a minimum number of 200 citations. Source: The author, based on WoS 2019.

This co-citation study continued with the analysis of the main authors. Specifically, this analysis, illustrated in Figure 5 reveals the existence of six clusters. The main red cluster with 46 members, was led by the four most co-cited authors, specifically Parasuraman ( 832 citations), Oliver (673 citations), Zeithaml (611), and Fornell (595). However, it also included another three of the main co-cited authors, specifically Croning (422 citations), Petrick (441), and Hair (391), in the positions six, seven, and nine of the top co-cited authors. The main topics of most of these authors were marketing research in general, and also the use of methodological instruments such as structural equation models, as explained previously. The second cluster, in green with 33 authors, was led by Hall, the fifth most co-cited author, with 515 citations. This group also included important authors in tourism and hospitality management and planning, who emphasized the relevance of service quality, and also ecological and environmental 
impacts, and questions related to sustainability. This was the case of Hall, the fifth most cited author (515 citations), and others such as Ryan, Getz, and McKercher. All of them were among the 20 top authors with most co-citations in the study. Chen, the eighth author with the most citations (411) in the co-citation analysis of authors, led the third main cluster, in blue with 26 members. This group was also made up by Kozak, Baloglu, and Crompton, also among the top 20 authors with most citations. Their perspective again emphasized the relationship between quality, satisfaction, intentions, and other customer behavior, focusing on a marketing perspective but with papers focused on the tourism and hospitality industry and tourism destinations. The yellow cluster was led by Gursoy and Anderek, also inside the 20 top main authors according to the citation criteria of this ranking. The main works in this cluster were by Gursoy focusing on resident attitudes and the relevance of tourism on enhancing the quality of life, while Anderek, a professor of sustainable tourism also concentrated on the perceptions and quality of life, mainly of residents. The fifth cluster with just 10 authors in violet, was led by Buhalis, the tenth author with most citations (351), and also included Law, an author outside the 20 top authors of the ranking. These authors, who shared many works, concentrated essentially on the relevance of information technologies and social media, and its strategic use for management in tourism and hospitality. Finally, the residual light blue cluster, with only six authors, included Connell, Reisinger, or Hofstede, authors interested in socio-cultural perspectives and differences between people.

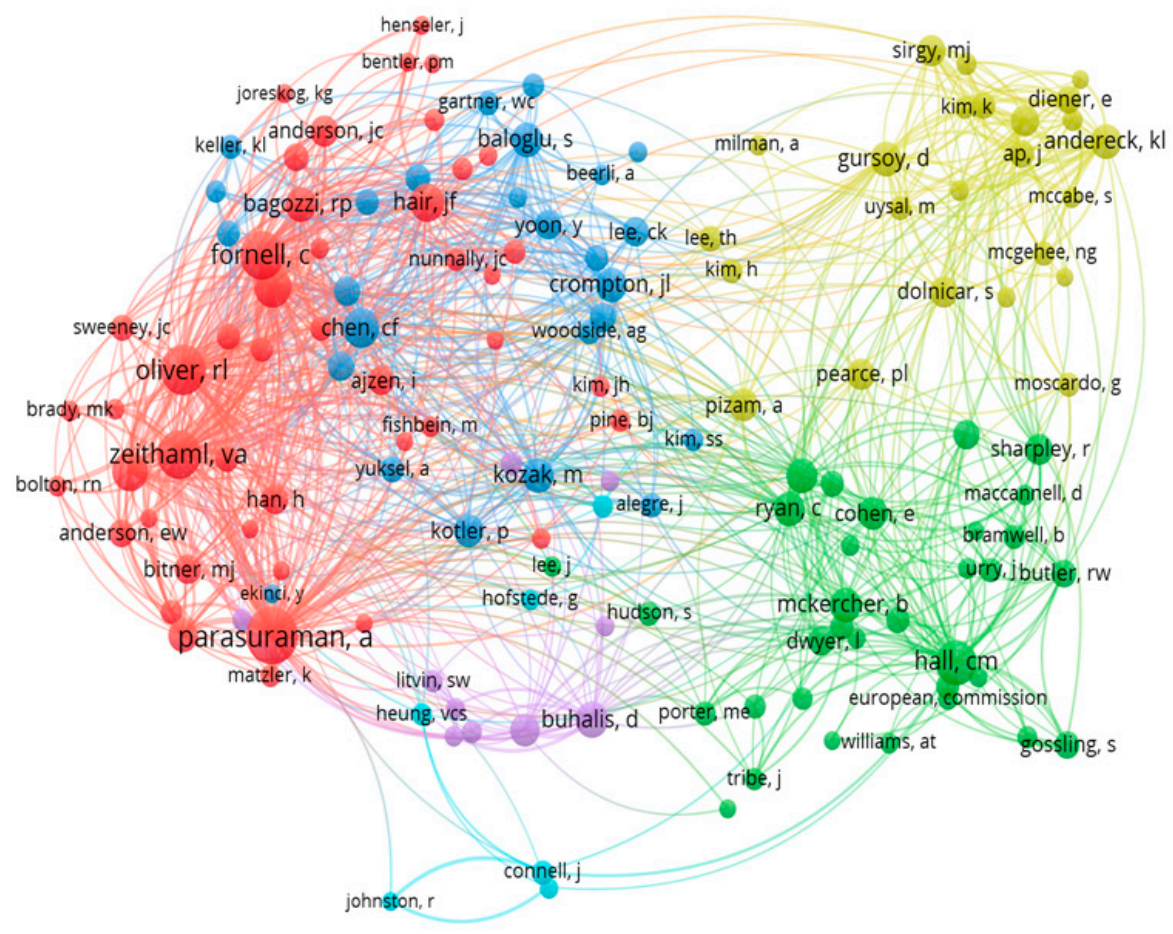

Figure 5. Author co-citation network on TQ. One hundred and forty-five authors, of the 96,148 cited authors, which met the threshold of a minimum number of citations of 100 . Source: The author, based on WoS 2019.

\subsection{Bibligraphic Coupling of Authors}

Another perspective of analyzing author relatedness is by studying bibliographic coupling. This concept, explained by [43], counts the number of references a group of documents have in common (articles A and B are coupled if both of them cite another article C). The analysis is summarized in Figure 6. Observing the strength and number of documents, the rank was led by Law (1523 link strength, 34 documents), Kim, H (1074 1.s., 14 doc.), Uysal (1073 1.s., 16 doc.), CK.Lee (983 1.s., 19 doc.), and Petrick (912, 1.s., 16 doc.). There were 10 main clusters. The red one, with 28 authors, did not include any of the main 20 top authors on the study's list, but Huang S. (15th according to the 1.s. 
criterion) although it included Kozak, McKercher, and Ryan, as explained in the previous epigraph, although the main perspective was a managerial focus on tourism, this cluster had a diverse focus perspective, although with tourism and hospitality research as the main focus. The second cluster, with 18 items in green, included the main authors of this ranking, R. Law, and also included J. Li, S. Li, S. Kim L. Wang, and Buhalis, all of them among the 20 top main authors according to the L.S. criteria. As pointed out previously, their main focus was the analysis of information technologies in tourism. The third cluster, with items, in dark blue, included Ck Lee, H. Han, S. Lee, and N. Chung, classified 4th, 6th, 7th, and 9th in the ranking, and M.J. Kim, was also within the 20 top main authors. This cluster also had a technological perspective, associated with motivations and customers' attitudes. The fourth cluster, also with 10 items and in yellow, did not include any of the 20 top main authors according to the rank. The fifth cluster, in violet, with eight items, neither. However, the authors in this cluster focused on medical tourism from a health science perspective, which was a relevant new area. The sixth group, with seven authors, in light blue, included H. Kim and Uysal, the second and third main authors in this ranking, and also Woo, classified tenth. Their main focus was the quality of life, residents' attitudes and well-being. The seventh cluster, in orange, was led by Anfuso, number 14th in the list, but no other main author in the list, although the illustrations also showed Saayman and Willliams. The main focus of Anfuso was the environmental quality of beaches and coasts, while Saayman focused on the quality of tourism products and its incidence on tourism demand from an economic perspective. The eighth group, with five items was led by Alvarez-García and De la Cruz del Rio-Rama, ranked 17th and 18th in the list. They focused on service quality, quality management, and the relevance of certifying quality for tourism. Some of the authors in this group also concentrated on environmental management for tourism development. The cluster in dark pink was led by Petrick, the fifth author, who focused on tourism marketing. This group also had four authors, one more than the last cluster, which with three items and in light pink was led by L. Su, the eighth author in the classification.

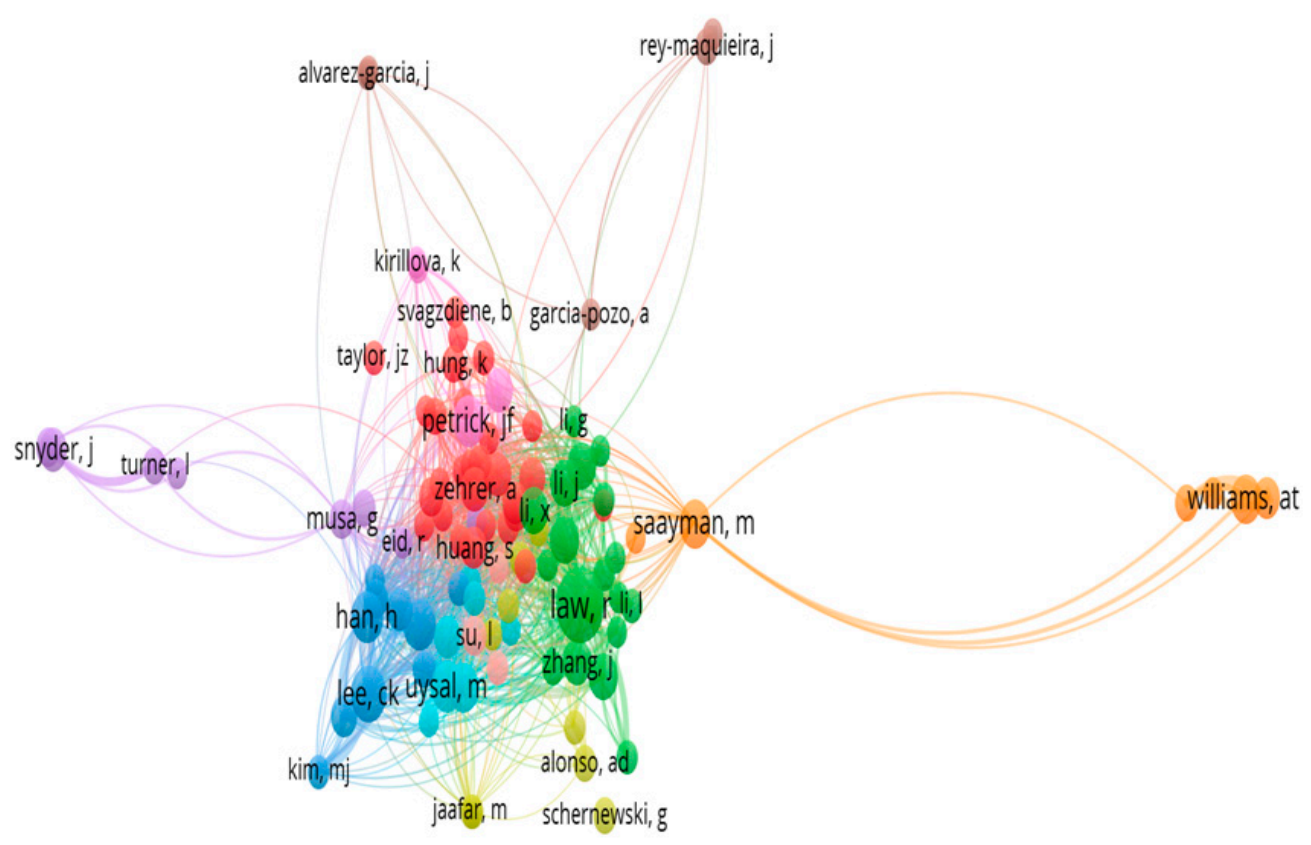

Figure 6. Bibliographic coupling of authors. Ninety-nine authors, of the 10,270 authors, which met the threshold of a minimum number of documents of an author of six. Source: The author, based on WoS 2019.

\subsection{Country and University Co-Author Analysis}

Normally, bibliometric analysis also emphasizes co-authorship analysis in order to focus on the structure of research collaboration, essentially between countries and universities, with the aim of 
analyzing the behavior of research teams [52]. Therefore, the distance between nodes and the thickness reveal the degree of collaboration between countries and universities, while their influence is shown in the diverse nodes.

Focusing on the networks of countries, the VOS-viewer program revealed that the literature was led (Figure 7) by The USA (735 documents, 17,446 citations), and was followed by Spain (491 documents, 6118 citations) China (449 documents, 5020 citations), Australia (358 documents, 9765 citations), and England (299 documents, 8836 citations; the program separates England, Scotland, and Wales, instead considering UK, and for instance includes Wales in the cluster led by Spain). The five main countries led three of the nine clusters observed in the study. Other top countries were Taiwan, which although it was the 11th according to the link strength contributes with 252 documents to the list (2721 citations), Italy (232 documents, 2329 citations), Turkey (177 documents, 1594 citations), South Korea (172 documents, 2457 citations), and Canada (163 documents, 7182 citations). According to the link strength, Portugal (150 documents, 1365 citations), and Germany (112 documents, 1573 citations) could also be mentioned. In addition, it could be stated that the relevance of the Netherlands and Mexico, which, although only including 81 and 66 documents, receive 2029 and 2707 citations respectively. However, the cluster with most components was the one led by Turkey and also Germany, with 14 countries in red. This cluster mainly included east European countries. This was followed by the green cluster led by Canada, with 12 countries, mainly from north Europe; and the dark blue cluster, led by Spain that also included 12 countries, mainly from South America. The yellow cluster included 10 countries, mainly from Asia. The violet cluster included nine countries, mainly Muslim countries from Asia. The light blue cluster was led by Italy and included seven countries from Europe and Africa; South Korea and France led a dispersed orange cluster with six countries. The eighth main cluster was brown, with six countries, including some of the top countries in our study, such as China, England, and Taiwan. Finally, the last cluster, in pink, and with only five countries, was the one led by the USA, in the centre of the plot, also including Australia and Portugal as relevant countries.

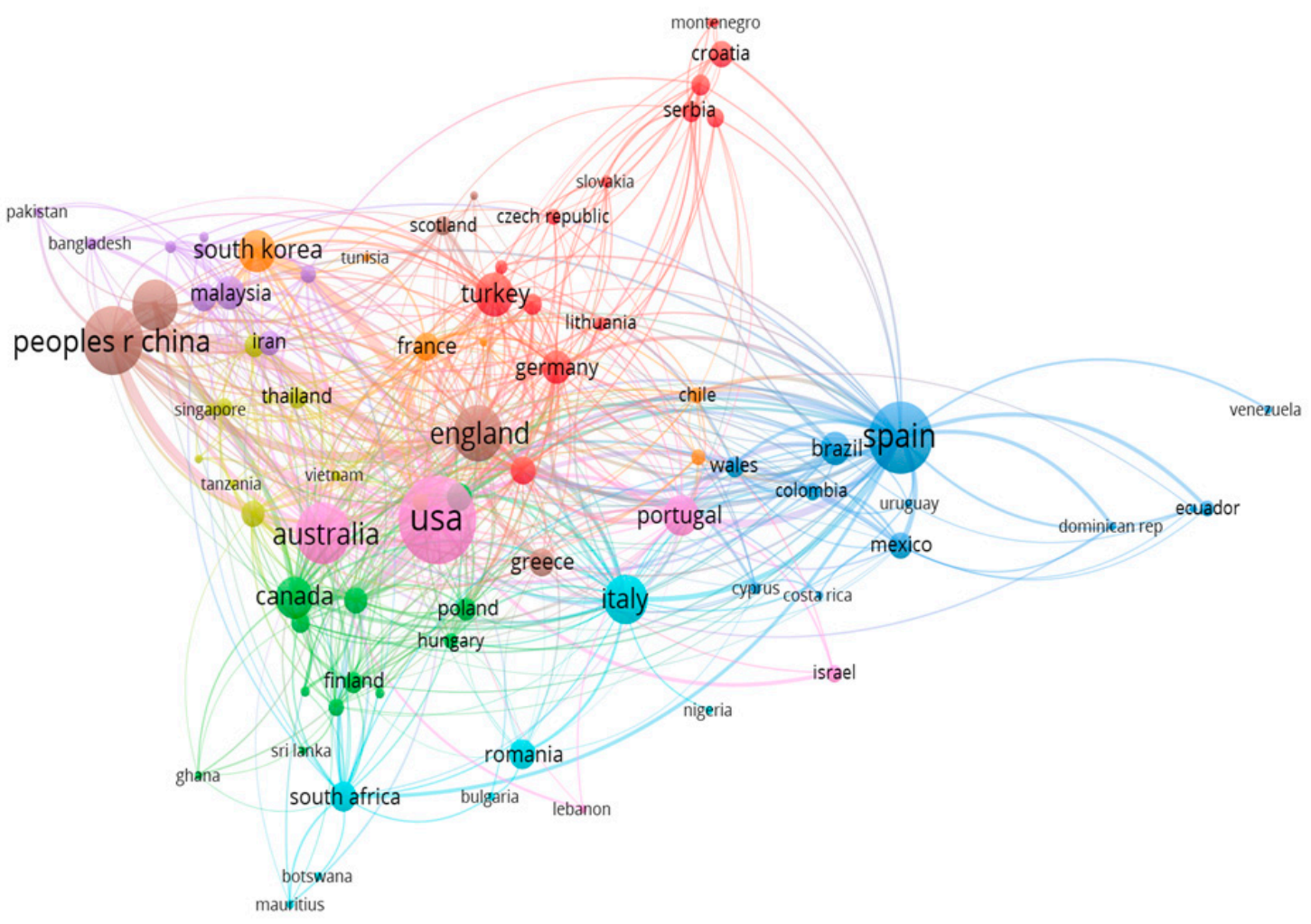

Figure 7. Countries co-authorship network of TQ. Eighty-three countries, of the 144 nations, which met the threshold of a minimum number of five papers about a country. Source: The author, based on WoS 2019. 
Finally, the research studied the most relevant institutions in TQ related publications (Figure 8). In the study, the 10 top leading universities were Hong Kong Polytechnic University (133 documents, 2459), Griffith University (50 documents, 691 citations), Kyung Hee University (South Korea, 48 documents, 910 citations), University of Central Florida (47 documents, 456 citations), University of Queensland (39 documents, 3110 citations), Texas A\&M University (38 documents, 2360), Chinese Academy of Sciences (37 documents, 651 citations), Universidade do Algarve (Portugal, 33 documents, 321 citations), James Cook University (32 documents, 399), and Sun Yat Sen University (31 documents, 241 citations). However, the illustration indicates a big dispersion of relationships, showing 14 clusters. Hence, the main cluster, in red, on the right side of the plot and 18 universities, did not include any of these top universities, including mainly European Universities. The second cluster, in dark green and 12 institutions, was central in the plot and was led by Texas A\&M University, mainly including USA universities. The third cluster, in blue and 10 institutions, also central in the plot was led by University of Waterloo (Canada, 30 documents, 1223 citations), including seven Spanish universities. The fourth cluster, with nine centers, and at the top in the illustration, did not include any of the leading centers, including for example Penn State University. The plot indicated two violet clusters, the main one, in dark violet was the fifth cluster, led by Griffith University and University of Algarve. The light violet only included Hong Kong Polytechnic University, and two other institutions, being the cluster with least members. University of Queensland led the light blue cluster (with eight institutions), while the seventh cluster, with seven institutions in orange (at the bottom left) was made up mainly by Australian institutions. James Cook University led the eighth cluster with seven institutions, and the Chinese Academy of Science, in pink, the ninth one (also with seven centers). The tenth cluster, with six institutions was the one led by Kyun Hee University.

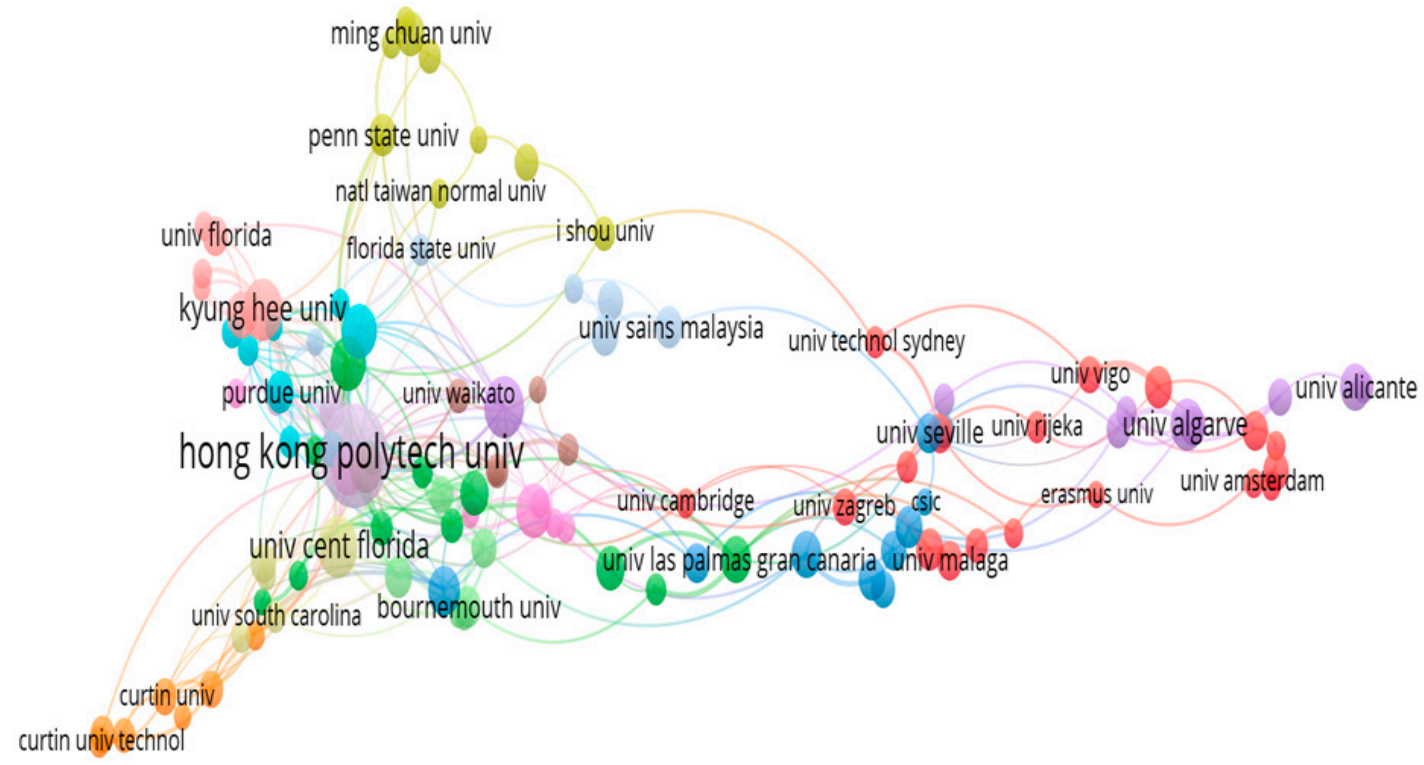

Figure 8. Institutions co-authorship network of TQ. One hundred and twenty organizations, of the 3610 , met the threshold of a minimum of 10 documents. Source: The author, based on WoS 2019.

\section{Discussions}

The purpose of this article was to analyze the importance of tourism and quality. Hence, the paper studied and defined this issue theoretically, observing the relevance of quality on destinations, organizations, hosts, and also on tourists. Therefore, the paper analyzed the topic of tourism and quality, observing the diverse advances in the literature and considering it as a multidimensional area than encompass wellbeing (physical, material, ecological, social, or even emotional) of those destination and the diverse stakeholders involved in the production or consumption of tourism goods and services, and also the features of performance of the tourism product or service as it was expected, 
perceived, or experienced by the tourist. The paper also concentrated on the search for previous analysis of the structure of the field of tourism and quality, focusing on the existence of previous bibliometrics. Nevertheless, no bibliometric study or visualization analysis about research on quality in tourism was found. Observing this lack, and also the relevance of the bibliometric approach, our work developed a bibliometric and visualization analysis of TQ related documents.

The results of our analysis examined the need to observe the field from an interdisciplinary perspective that could integrate, environmental, social, economic, and essentially managerial and marketing perspective dimensions of TQ. The research shows that after several conceptual, and also methodological papers, essentially related to structural equation models, the question could be developed by focusing on other perspectives and trends, by focusing on other methodological instruments, and more applied and empirical research to analyze diverse specific questions related to the topic.

Research about tourism and quality has been developing regularly since 1989, however, it has experienced a huge growth recently, especially in the last decade, with almost 800 documents annually in the last two years, when till 2008 they not surpassed 100 published papers a year. However, the literature is still scarce, compared to other topics, this paper being pioneering in analyzing the structure and trends in the research.

The increasing importance of TQ was reflected in the number of citations. Hence, the most cited paper in tourism field, the one by [12], had almost 2500 citations in the WoS. Moreover, there were another three papers, that also received more than 500 citations, although they were relatively recent papers, as they were published in the 21st century, but the fourth one was published in 1999. These results emphasized the recent relevance of TQ.

Examination of the sources indicated that the top journals in the area were Tourism Management, Journal of Travel Research, Journal of Travel and Tourism Marketing, and Sustainability. Moreover, the results indicate that the main categories of publications were Hospitality, Leisure Sport and Tourism, Management, and Environmental Sciences, although it is expanding across multiple academic disciplines.

The keywords co-occurrence revealed that "tourism", "satisfaction", "service quality", "medical tourism", "quality of life", and "sustainability" were the most frequent keywords. This indicated the relevance of "service quality" and "quality of life" as the main factors observed, and also the relevance of managerial, marketing, medical, and environmental perspectives. A review of the keywords revealed the relevance of managerial and destination management issues ("service quality", "quality of life", "quality", and "rural tourism"), marketing perspectives ("satisfaction", "service quality", "customer satisfaction", "perceived value", and "loyalty"), also medical ("medical tourism"), environmental issues ("water quality", and "environmental change"), and especially the relevance of sustainability ("sustainability", "sustainable tourism", and "sustainable development"). These results stress the relevance of quality as an important topic in the tourism management literature and as one of the core topics of sustainability and environmental sciences, such as it was previously explained in the literature review. This co-occurrence analysis also included some of the most important places of research ("China", and "Spain") and the emerging areas ("nature based tourism", and "social media").

Co-citation analysis indicated that the article by Fornell and Larcher [37] and another two articles by Parasuraman et al. $[15,16]$, led the rank of the top cited papers of the 4625 documents in the database. They were methodological papers, the first was about structural equation models, and the other two were about service quality in general, its conceptualization and measurement with a marketing focus. This study revealed the relevance of diverse clusters, with the same perspectives observed previously (management, marketing, environmental ... ), observing also one cluster about information technology and social media.

The journal co-citation network illustrated four clusters of journals: The main one, led by Journal of Marketing and most of the journals of the selected list included journals oriented to management and marketing; the second one, led by Tourism Management and other relevant sources in the tourism 
literature, observed mainly a tourism centered perspective; the third one, led by Thesis (outside the main journals) mainly observed an environmental-ecological orientation; and the fourth reduced cluster led by Tourism Economics was associated with an economic perspective.

The author co-citation study indicated six clusters. The main cluster led by Parasuraman and the other three most co-cited authors included research in the area of marketing in general, and also the use of methodological instruments. The second cluster, led by Hall, included important authors in tourism and hospitality management and planning, including diverse areas such as service quality, ecological, and environmental impacts, and topics related to sustainability. Other clusters essentially dealt with marketing issues in tourism (Chen), the impact of tourism on residents' quality of life (Gursoy), the strategic use of information technologies and social media (Buhalis), socio-cultural perspectives, and differences between people (Connell).

The bibliographic coupling of authors indicated the existence of ten clusters of authors. The main one did not include any of the 20 top authors, the main perspective being a managerial focus on tourism. The second cluster, led by R. Law, was focused on the analysis of information technologies in tourism. The third cluster (Ck Lee) also observed a technological perspective, mainly associated with customers' attitudes. Other clusters had medical tourism and health sciences, quality of life and residents' well-being, environmental quality of coasts and products and economic demand, quality certifications and environmental management, and tourism marketing perspectives.

The co-authorship analysis of TQ showed the prevalence of the USA, Spain, China, Australia, and England, leading three of the main clusters. The analysis observed a main cluster of east European countries led by Germany; other group of north European countries, which included and was led by Canada; and another group of South American countries, led by Spain. Other clusters showed Muslim countries from Asia, countries from Europe and Africa, a dispersed cluster, and another two clusters, one related to England and China, and the other to the USA and Australia. The study indicated that the top institutions analyzing the tourism field were Hong Kong Polytechnic University, Griffith University, and Kyung Hee University. The analysis also observed a big dispersion of relationships, showing 14 clusters. The main results only showed the relevant collaboration among European Universities, USA Universities, and Spanish Universities.

\section{Concluding Remarks}

This study on TQ related documents indicated that this area was very broad and varied, which should integrate and reconcile diverse perspectives. These perspectives essentially come from managerial, but also form environmental areas, observing sustainability issues a core relevance. In this vein, the article indicated the different lines of research in $T Q$, their relative importance, and some interesting trends in the literature. These results are important for practitioners when considering different policies, and especially important to researchers, as the study observes connections and differences between the diverse areas studying $T Q$, and some topics that can open new areas of research.

Focusing on policy makers and practitioners, the diverse perspectives cannot be avoided during the planning and management of organizations and destinations. Hence, they should include, comprise, and integrate the complexity of the area. In particular, social (i.e., quality of life, and tourist satisfaction), environmental-ecological (i.e., water quality, and climate change), managerial, economic, and marketing (i.e., service quality, and destination image) perspectives should be incorporated, and also medical ones, differences of cultures, and the relevance of information technologies and social media, as was pointed in this bibliometric analysis of the literature about TQ. Our results also indicated that some of these perspectives were shared with some of the main areas of the sustainability literature in the tourism sector as it was illustrated in a recent bibliometric study [4]. In addition, new starting themes such as perspectives related to new technologies and social media impacts should be included in the development of organizational and destination management improvements.

Observing the theoretical relevance of this article, our bibliometric analysis could help researchers advance in their investigations about TQ. Following Lai et al. [53] (p. 31), "Knowing more about 
tourism problems can enhance the understanding of factors that affect tourism knowledge production". Moreover, according to these authors, the understanding of tourism problems has a relevant influence on which tourism problems to solve, influencing the initial or early stage of tourism research [53]. In this respect this paper can offer new trends in research, and help authors to discover new possible areas or areas where the research on TQ is still scare. Following Garrigos et al. [4], these aspects could be explained by three questions: Questions related to trends in TQ in the classical areas of research, the development of new areas where TQ has not been developed yet, and the expansion of fashionable questions that can be considered related to TQ. Focusing on these aspects, first of all the development of TQ research observed in this study showed that TQ had developed in some classical areas such as management and marketing, and it was also developing in areas such as medicine, economics, and environmental sciences, showing a close relationship with sustainability issues (actually, sustainability, sustainable tourism, and sustainable development were some of the main topics of research in the TQ field according to the results of this paper). In addition, the study observed that there was a lack of diverse classical fields related to sciences or social sciences, which were not relevant in the current literature. Hence they need more research. In particular, there is a lack in fields such as physics, mathematics, biology, sociology, and geography. Secondly, new areas for research, expanding now in academia, were not observed in a relevant way in TQ, which offer new opportunities, especially in questions related to information technologies, engineering, social media, or open innovation (which are offering new relevant trends). This is a fact that can help researchers to focus on these questions (in this vein, TQ should evolve towards the most popular areas in general academia). This study could also add areas within management or marketing fields such as innovation or entrepreneurship or ethics. Thirdly, the analysis of the works with most influence or with most citations by the TQ papers, or the ones that receive more citations among our sample, or the more relevant keywords (or the keywords that are increasing) can help researchers to see the most fashionable research questions, with more possibilities to be accepted by the diverse journals. Hence, the most cited papers could provoke the development of more papers on topics related to TQ that can be accepted as they can have more impact or citations in the future. In addition, of these three questions, the study has to add, especially, the need for more empirical and methodological articles, related to new indicators of TQ and more methodological papers that use new techniques especially apart from structural equation models.

Apart from these conclusions, this article obviously has diverse limitations that can help to promote further research. In this respect, our methodology of using bibliometric and visualization analysis has limitations as it was based on the objective treatment of keywords that could provoke confusing results if they were not complemented with more qualitative and focused studies. We have to add the limitations of our sample, as it only considered the works used in the WoS Collection, and also only considered articles, reviews, letters, and notes. In this respect, the study did not include some works like proceedings, professional documents, or theses, nor documents from other databases (for instance in other languages apart from English, which although secondary in the "fashionable" worldwide literature, could offer us interesting and pioneering trends). Hence, the extent of this research to include these databases and documents can also offer further new interesting analyses.

Future studies should also focus on some of the trends observed in the different analyses developed in this work. In addition, they could concentrate on some of them, by developing them with a deep focus. For instance, they could observe the evolution of the diverse keywords in the literature, or concentrate on a deep analysis of some of the clusters or themes of research detected in our studies. Moreover, new papers could also consider new methodologies (inside or outside bibliometric analyses) to structure and study the literature about TQ. Furthermore, they can use other software to study bibliometrics, or develop other possibilities that the VOSviewer also permits (i.e., more bibliographic coupling, co-citations, or co-authorship analyses). All these works should extend, enrich, and complement our work. 
Author Contributions: The research is designed and performed by F.J.G.-S. The data was collected by F.J.G.-S. and Y.N.-K. Analysis of data was performed by F.J.G.-S., Y.N.-K. and Y.N. Finally, the paper is written by F.J.G.-S., Y.N.-K. and Y.N. All the authors read an approved the final manuscript.

Funding: This research was funded by Universitat Politècnica de València, Universitat Jaume I. and The APC was funded by Walailak University.

Acknowledgments: The authors would like to thank Universitat Politècnica de València, Universitat Jaume I, and Walailak University for supporting this research.

Conflicts of Interest: The authors declare no conflict of interest.

\section{References}

1. Armenski, T.; Dwyer, L.; Pavluković, V. Destination competitiveness: Public and private sector tourism management in Serbia. J. Trav. Res. 2018, 57, 384-398. [CrossRef]

2. González, M.R.; Sasidharan, V.; Álvarez,J.A.; Azpeitia, L.D. Quality and sustainability of tourism development in Copper Canyon, Mexico: Perceptions of community stakeholders and visitors. Tour. Manag. Persp. 2018, 27, 91-103.

3. Broadus, R. Toward a definition of "bibliometrics". Scientometrics 1987, 12, 373-379. [CrossRef]

4. Garrigos, F.S.; Narangajavana, Y.K.; Lengua, I.L. Tourism and sustainability: A bibliometric and visualization analysis. Sustainability 2018, 10, 1976. [CrossRef]

5. Hall, C.M. Publish and perish? Bibliometric analysis, journal ranking and the assessment of research quality in tourism. Tour. Manag. 2011, 32, 16-27. [CrossRef]

6. Benckendorff, P.; Zehrer, A. A network analysis of tourism research. Ann. Tour. Res. 2013, 43, 121-149. [CrossRef]

7. Yuan, Y.; Gretzel, U.; Tseng, Y.H. Revealing the nature of contemporary tourism research: Extracting common subject areas through bibliographic coupling. Int. J. Tour. Res. 2015, 17, 417-431. [CrossRef]

8. Barrios, M.; Borrego, A.; Vilaginés, A.; Ollé, C.; Somoza, M. A bibliometric study of psychological research on tourism. Scientometrics 2008, 77, 453-467. [CrossRef]

9. De la Hoz, A.C.; Muñoz, F.L.; Bakucz, M. Past themes and future trends in medical tourism research: A co-word analysis. Tour. Manag. 2018, 65, 200-211. [CrossRef]

10. García, F.L.; Claver, E.C.; Úbeda, M.G.; Marco, B.L.; Zaragoza, P.C.S. Mapping the "intellectual structure" of research on human resources in the "tourism and hospitality management scientific domain" Reviewing the field and shedding light on future directions. Int. J. Cont. Hosp. Manag. 2018, 30, 1741-1768. [CrossRef]

11. Buhalis, D. Marketing the competitive destination of the future. Tour. Manag. 2000, 21, 97-116. [CrossRef]

12. Hoegh, O.G.; Mumby, P.J.; Hooten, A.J.; Steneck, R.S.; Greenfield, P.; Gomez, E.; Knowlton, N.; Eakin, C.M.; Iglesias, R.P.; Muthiga, N.; et al. Coral reefs under rapid climate change and ocean acidification. Science 2007, 318, 1737-1742. [CrossRef] [PubMed]

13. Baker, D.A.; Cromptonb, J.L. Quality, satisfaction and behavioral intentions. Ann. Tour. Res. 2000, $27,785-804$. [CrossRef]

14. Bigne, J.E.; Sanchez, M.I.; Sanchez, J. Tourism image, evaluation variables and after purchase behaviour: Inter-relationship. Tour. Manag. 2001, 22, 607-616. [CrossRef]

15. Parasuraman, A.; Zeithaml, V.A.; Berry, L.L. SERVQUAL: A multiple-item scale for measuring consumer perceptions of service quality. J. Retail. 1988, 64, 12-40.

16. Parasuraman, A.; Zeithaml, V.A.; Berry, L.L. A conceptual model of service quality and its implications for future research. J. Market. 1985, 49, 41-50. [CrossRef]

17. Reeves, C.A.; Bednar, D.A. Defining quality: Alternatives and implications. Acad. Manag. Rev. 1994, 19, 419-445. [CrossRef]

18. Garvin, D.A. Managing Quality: The Strategic and Competitive edge; The Free Press: New York, NY, USA, 1988.

19. Feigenbaum, A.V. Quality and business growth today. Qual. Prog. 1982, 15, 22-25.

20. Kandampully, J. The impact of demand fluctuation on the quality of service: A tourism industry example. Manag. Serv. Qual. 2000, 10, 10-19. [CrossRef]

21. Williams, C.; Buswell, J. Service Quality in Leisure and Tourism; Cromwell Press: Wallingford, UK, 2003; pp. 205-206.

22. UNWTO. "Quality". Available online: http://sdt.unwto.org/en/content/quality (accessed on 7 January 2019). 
23. Uysal, M.; Sirgy, M.J.; Woo, E.; Kim, H.L. Quality of life (QOL) and well-being research in tourism. Tour. Manag. 2016, 53, 244-261. [CrossRef]

24. Garrigós-Simón, F.J.; Galdón-Salvador, J.L.; Gil-Pechuán, I. The economic sustainability of tourism growth through leakage calculation. Tour. Econ. 2015, 21, 721-739. [CrossRef]

25. WCED. Our Common Future; Oxford University Press: Oxford, UK, 1987.

26. Honarpour, A.; Jusoh, A.; Md Nor, K. Total quality management, knowledge management, and innovation: An empirical study in R\&D units. Tot. Qual. Manag. Bus. Excel. 2018, 29, 798-816.

27. Prayag, G. Tourists' evaluations of destination image, satisfaction, and future behavioral intentions-The case of Mauritius. J. Trav. Tour. Market. 2009, 26, 836-853. [CrossRef]

28. Ryan, C. Seeking quality in pacific tourism. In Tourism in the Pacific: Issues and Cases, 1st ed.; Hall, C.M., Page, S.J., Eds.; International Thomson Business Press: London, UK, 1996; pp. 146-160.

29. Zeithaml, V.A.; Berry, L.L.; Parasuraman, A. The behavioral consequences of service quality. J. Market. 1996, 60, 31-46. [CrossRef]

30. Zeithaml, V.A.; Bitner, J.M. Services Marketing: Integrating Customer Focus across the Firm, 3rd ed.; McGraw-Hill: New York, NY, USA, 2002.

31. Shostack, G.L. How to Design a Service. Eur. J. Market. 1982, 16, 49-63. [CrossRef]

32. Crompton, J.L.; Love, L.L. The predictive validity of alternative approaches to evaluating quality of a festival. J. Trav. Res. 1995, 34, 11-24. [CrossRef]

33. Wu, H.C.; Li, M.Y.; Li, T. A study of experiential quality, experiential value, experiential satisfaction, theme park image, and revisit intention. J. Hosp. Tour. Res. 2018, 42, 26-73. [CrossRef]

34. Atilgan, E.; Akinci, S.; Aksoy, S. Mapping service quality in the tourism industry. Manag. Serv. Qual. Int. J. 2003, 13, 412-422. [CrossRef]

35. Merigó, J.M.; Yang, J.B. Accounting research: A bibliometric analysis. Aust. Account. Rev. 2017, $27,71-100$. [CrossRef]

36. Delgado, E.L.C.; Robinson, N.G.; Torres, D.S. The Google Scholar experiment: How to index false papers and manipulate bibliometric indicators. J. Assoc. Inf. Sci. Technol. 2014, 65, 446-454. [CrossRef]

37. Cancino, C.; Merigó, J.M.; Coronado, F.; Dessouky, Y.; Dessouky, M. Forty years of Computers \& Industrial Engineering: A bibliometric analysis. Comp. Ind. Eng. 2017, 113, 614-629.

38. Blanco, F.M.; Merigó, J.M.; Gil, A.M.L. Fuzzy decision making: A bibliometric-based review. J. Intell. Fuzzy Syst. 2017, 32, 2033-2050. [CrossRef]

39. Merigó, J.M.; Gil, A.M.L.; Yager, R.R. An overview of fuzzy research with bibliometric indicators. Appl. Soft Comp. 2015, 27, 420-433. [CrossRef]

40. Hirsch, J.E. An index to quantify an individual's scientific research output. Proc. Natl. Acad. Sci. USA 2005, 102, 16569-16572. [CrossRef] [PubMed]

41. Van, N.J.E.; Waltman, L. Software survey: VOSviewer, a computer program for bibliometric mapping. Scientometrics 2010, 84, 523-538. [CrossRef] [PubMed]

42. Small, H. Co-citation in the scientific literature: A new measure of the relationship between two documents. J. Assoc. Inform. Sci. Tech. 1973, 24, 265-269. [CrossRef]

43. Kessler, M.M. Bibliographic coupling between scientific papers. J. Assoc. Inform. Sci. Tech. 1963, 14, $10-25$. [CrossRef]

44. Liao, H.; Tang, M.; Luo, L.; Li, C.; Chiclana, F.; Zeng, X.J. A bibliometric analysis and visualization of medical big data research. Sustainability 2018, 10, 166. [CrossRef]

45. Rigden, B.; Henry, L. Water quality and management for recreation and tourism. In Proceedings of the Iawprc Conference, Brisbane, Australia, 10-15 July 1988; Water Science and Technology; Pergamon Press: Oxford, UK, 1989; pp. R9-R10.

46. Chen, C.F.; Chen, F.S. Experience quality, perceived value, satisfaction and behavioral intentions for heritage tourists. Tour. Manag. 2010, 31, 29-35. [CrossRef]

47. Fornell, C.; Larcher, D.F. Evaluating structural equation models with unobservable variables and measurement error. J. Market. Res. 1981, 18, 39-50. [CrossRef]

48. Yoon, Y.; Uysal, M. An examination of the effects of motivation and satisfaction on destination loyalty: A structural model. Tour. Manag. 2005, 26, 45-56. [CrossRef]

49. Zeithaml, V.A. Consumer perceptions of price, quality, and value: A means-end model and synthesis of evidence. J. Market. 1988, 52, 2-22. [CrossRef] 
50. Cronin, J.J., Jr.; Brady, M.K.; Hult, G.T.M. Assessing the effects of quality, value, and customer satisfaction on consumer behavioral intentions in service environments. J. Retail. 2000, 76, 193-218. [CrossRef]

51. Anderson, J.C.; Gerbing, D.W. Structural equation modeling in practice: A review and recommended two-step approach. Psychol. Bull. 1988, 103, 411-423. [CrossRef]

52. Reyes, L.G.; Gonzalez, C.N.B.; Veloso, F. Using co-authorship and citation analysis to identify research groups: A new way to assess performance. Scientometrics 2016, 108, 1171-1191. [CrossRef]

53. Lai, K.; Li, J.; Scott, N. Tourism problemology: Reflexivity of knowledge making. Ann. Tour. Res. 2015, 51, 17-33. [CrossRef]

(c)

(C) 2019 by the authors. Licensee MDPI, Basel, Switzerland. This article is an open access article distributed under the terms and conditions of the Creative Commons Attribution (CC BY) license (http://creativecommons.org/licenses/by/4.0/). 